\title{
An Overview of the Tissue Engineering Market in the United States from 2011 to 2018
}

\author{
Yu Seon Kim, BS,,$^{1, *}$ Mollie M. Smoak, BS, ${ }^{1, *}$ Anthony J. Melchiorri, PhD, and Antonios G. Mikos, PhD ${ }^{1,2}$
}

This report seeks to provide an update of the tissue engineering industry from 2011 to 2018. Public tissue engineering companies with a presence in the United States were the focus of this report due to the publicly accessible financial data that they provide on an annual basis. Over the course of this analysis, 49 tissue engineering companies were identified, 21 of which were in the commercial phase of development and had tissue engineering products on the market. These 21 companies made an estimated $\$ 9$ billion in sales of tissue engineering-related products in 2017. Based on previous reports and market trends, the field of tissue engineering is forecasted to continue to build revenue for the years to come.

Keywords: tissue engineering, regenerative medicine, industry, market, company

\section{Impact Statement}

This report seeks to provide an update of the current landscape of the tissue engineering market in the United States from an unbiased point of view by analyzing the financial reports provided by tissue engineering companies, as well as data from publicly available clinical trials with relevant tissue engineering applications.

\section{Introduction}

$\mathbf{S}_{\text {ithen }}$ INCE THE TERM tissue engineering was coined in 1993, ${ }^{1}$ the fields of tissue engineering, regenerative medicine, and cell therapy have greatly matured from benchtop ideas to commercially available products that are widely used in the clinic. We broadly define tissue engineering as the culmination of engineering and biology to advance the restoration or improvement of tissue function. Artificial organs, biomaterials, and cell therapies that leverage autologous or donor cells have been utilized for regenerative purposes. Currently, the terms "tissue engineering" and "regenerative medicine" bring up $\sim 1.2$ and 0.6 million results on Google Scholar, respectively. This indicates how much the field has grown in only 25 years.

Tissue engineering is highly interdisciplinary, pulling ideas from biology, chemistry, materials science, engineering, medicine, and many more areas toward the goal of regenerating whole organs or tissues. It is therefore crucial to strictly define the specific range of business activities that this review will investigate. In this study, we based our search for tissue engineering, regenerative medicine, and cell therapy (collectively abbreviated as TE) using the keywords and criteria used previously by Jaklenec et $a .^{2}$ It is important to recognize the work of Mason et al. and their efforts to review the industry of cell therapy. ${ }^{3,4}$ While their reviews distinguish cell therapy from tissue engineering and regenerative medicine, this review does not.

In their latest update on the TE industry, Jaklenec et al. concluded that the TE market was stabilizing and predicted smoother growth as it continues to mature. ${ }^{2}$ In an effort to provide an update on the current status of the TE industry, an extensive financial analysis of the current TE-related companies, similar to what has been done previously, was attempted. However, access to financial information for private and international companies was limited. Private companies are not required to provide publicly-available financial documents. In addition, many international companies do not have easily accessible company and financial information. To enhance the accuracy and reproducibility of the company database, the scope of our analysis was limited to only public companies with a principal office in the United States.

In addition to previously attained financial data, TE-related clinical trials were surveyed to obtain an understanding of the

\footnotetext{
${ }^{1}$ Department of Bioengineering, Rice University, Houston, Texas.

${ }^{2}$ Biomaterials Lab, Rice University, Houston, Texas.

*Both authors contributed equally to this work.
} 
research and development (R\&D) efforts that are being conducted in the field. Due to differences in methods from previously published articles on reviewing the TE market, a direct comparison cannot be made. However, we believe that the analyses that are provided in this article will build an accurate picture of the current TE industry within the U.S. public domains, which in turn may provide insight into the global TE market.

\section{Methods}

\section{Compiling the company list}

A list of public tissue engineering companies was compiled in the following way:

1. The latest version of this report was used as a guide. ${ }^{2}$ Each of the companies reported was verified or eliminated by visiting the company website and conducting Internet searches for mergers and buyouts.

2. Daily Google Alerts prompted from the terms "regenerative medicine," "stem cells," and "tissue engineering" were used between August 2017, when efforts to compile company data began, and March 2018, when the collection of data ended. This was used to gather information on mergers, buyouts, and startups that might have been overlooked by the other methods.

3. Clinical trials ongoing between June 2011, when the financial analysis in the previous publication was terminated, and March 2018 were explored prompted from the terms "tissue engineering," "regenerative medicine," "stem cell," "scaffold," and "hydrogel."

4. Internet searches were conducted to gather additional information about company status.

No new information that was brought to our attention occurring after March 2018 was considered in compiling the data.

\section{Company inclusion/exclusion criteria}

Our list of companies included public TE companies with a presence in the United States and excluded private companies due to the limited access to accurate financial information. Public companies are required to disclose information annually in accordance with federal security laws. The U.S. Securities and Exchange Commission (SEC) requires domestic companies to file annual reports (10-k), which provide an accurate and widely available summary of the company's financial activity.

Within our list of public tissue engineering companies, corporations were refined based on our definition of tissue engineering and enabling technologies. Similar to previous reviews, we use tissue engineering and regenerative medicine interchangeably. Broadly, we included companies that combine engineering and biology to advance the restoration or improvement of tissue function. This definition excludes some stem cell companies that have become important to the advancement of the field of TE. Therefore, stem cell banking companies have been included in the compiled list because of their role as an enabling technology. Immunotherapies and therapies applied for cancer were excluded from our definition because they are outside the scope of our definition of TE.

A few gray areas were encountered when compiling this list. For example, contract research organizations were included if they provided services for other TE organizations.
However, third-party companies that sold equipment or goods that did not directly enable the progress of the TE aspects of a company were excluded. Companies that focused on the development of products for esthetic applications were excluded. In addition, not-for-profit cord blood banks, clinical services, veterinary firms, most tissue allografts, conventional bone marrow transplantation for cancer intervention, surgical sealants, ceramics, and transfusion medication were excluded from the compiled list.

Tissue allografts were excluded if they were (1) unmodified and minimally manipulated and (2) direct tissue-totissue matching for transplantation. For example, a bone graft to replace bone with no additional materials, growth factors, or cells added to the product to improve tissue regeneration would not be included. In contrast, isolated cell populations, treated or untreated with external factors, and then mixed with new materials (either synthetic or naturally derived) would be included if they were intended to induce tissue generation or repair.

Genetically modified cells or isolated cells were not included unless they were (1) differentiated into a new cell type or (2) included as part of another functional biomaterial within the scaffold. For example, modified or unmodified mesenchymal stem cells delivered in an injectable matrix scaffold intended to induce tissue regeneration would be included. Businesses that provide education, media-based services, or financial services were also excluded. Overall, therapies that do not provide or enable regenerative or reconstructive function to damaged tissues were excluded.

The products of each company, as outlined in their annual financial reports and on their company websites, were evaluated based on the type of therapy produced and the targeted effects. While some products were not explicitly marketed as regenerative therapies for regulatory purposes, the product was included if it was believed to promote cell migration, differentiation, infiltration, or regeneration within the body. For example, a decellularized tissue marketed as a structural material for wound healing would also promote cell infiltration and would, therefore, be included in our analysis. Other examples of TE products included materials (synthetic or naturally derived as well as autografts) that incorporated a bioactive component, such as live cells or active growth factors.

\section{Gathering company data}

The data reported here were collected predominantly by using publicly available 10-k forms either through the company website or through EDGAR SEC filing website (https://www.sec.gov/edgar/searchedgar/companysearch.html). Within the 10-k form, important company information, such as location of the principal executive office, development stage, spending, revenue, and number of employees can be easily found. Latest 10-k annual reports filed by the companies were used to collect the aforementioned data. We identified TE-specific sales to the best of our ability by reviewing the descriptions for product lines and operating segments, and we selected the ones that were most relevant to TE (Supplementary Table S1; Supplementary Data are available online at www.liebertpub.com/tea).

Some financial segments were not subdivided by individual products or groups of products inclusive of only TEclassified products. Therefore, the smallest breakdown that 
could be found for TE products was used. However, we were unable to accurately segment the TE-specific spending and number of employees. Therefore, values for the entire company were reported instead.

The corporations were also categorized as "biomaterials," "cells and biomaterials," or "stem cells" based on the TE products and services that they provide as described on the company website and within the annual report. Companies that used predominately a material, including proteins and growth factors, for tissue engineering applications were classified as a biomaterials company. Companies that incorporate cells (autologous, allogeneic, or xenogeneic) into a biomaterial for tissue engineering applications were classified as a cells and biomaterials company. For those companies that used altered or unaltered stem cells alone, the classification of stem cells was used.

When reporting information on each company, all values were taken directly from company annual reports. The only data that were open to author interpretation were the segmenting of TE-relevant sales (Supplementary Table S1). A few companies reported were international companies that had a principal executive office located within the United States. For these companies, financial information was not always reported in U.S. dollar. To make comparisons for these companies, the exchange rate for the end of the filing period (December 31, 2017 in most cases) was used.

\section{Gathering clinical trial data}

Information about clinical trials is maintained by the National Library of Medicine at the National Institute of Health, and is available to the public through https:// clinicaltrials.gov. A search was conducted for interventional studies that either completed or were ongoing between June 2011 and March 2018. Studies that were terminated, withdrawn, or had unknown status were excluded from the list. We hoped this would provide insight into products and companies after the publication of the latest review. ${ }^{2}$

The following keywords were used to find studies: "tissue engineering," "regenerative medicine," "scaffold," "stem cell," and "hydrogel." The studies were then sorted into three categories based on the same criteria that were used to sort the TE industry data. While isolation, ex vivo expansion, and transplantation of stem cells are important enabling technologies for tissue engineering, they were excluded from the clinical trial data because of their indirect roles in TE. However, if cells were modified in any way for use in the reconstruction or restoration of a tissue, the study was included.

For each study, the therapy used and the application of the therapy were evaluated. If the therapy had a direct role in the restoration of a tissue and repair of function, it was included in the analysis. All cancer-related clinical trials (e.g., stem cell/T cell therapy for cancer treatment) were also excluded from our list. While many would consider immunotherapies that allow for treatment of a disease tissue engineering, we did not. Other treatments that were excluded include those targeting hernia repair with mechanical support only, viral vectors used for gene editing that did not directly play a role in regeneration of a tissue, and stem cells that were unaltered or did not have a direct effect on tissue repair.

Clinical trials that passed our inclusion criteria were further sorted by (1) study type (biomaterials, cells and biomaterials, and stem cells), (2) study phase, and (3) sponsoring organization (industry, academia, hospital, and government). In counting the number of clinical trials under each subcategory, if a clinical trial was in more than one study phase (e.g., both phase 1 and 2) or had more than one sponsors/collaborators, it was divided by the total number and then added under respective subcategories. This was to ensure that the sum of all subcategories would add up to be the actual total number of clinical trials.

We recognize that the data presented are not perfect and are subject to change as time progresses because of the rapid evolution and active culture of startups within the TE market. However, we believe that the data presented here are representative of current trends within the tissue engineering market place. We focused on the companies operating within the United States, so many large companies that do not operate within the United States were excluded. This was done to make the provided information more accurate and the methods more reproducible.

\section{Results}

Our in-depth analysis of the TE market space identified 49 publicly listed TE companies with a presence in the United States, which employed nearly 146,000 people. Of the 49 companies identified, 21 companies were in the commercial phase of development and were generating sales, which brought in an estimated $\$ 9$ billion in sales of TE-related products during the 2017 fiscal year. A compiled list of the companies that fit the above criteria can be found in Appendix Table A1.

Figure 1 shows a geographical heatmap of the locations of the headquarters for public TE companies in the United States. This is not a representation of overall TE company locations - only the principal executive offices. California occupies the greatest number of TE principal executive offices in the United States. This analysis divides companies based on the type of products they use and the development stage that they are currently operating under.

Figure 2 shows the total sales data and the sales data for TE products for the TE companies in the commercial stage based on product type (biomaterials, cells and biomaterials, and stem cells). Looking only at sales for TE-relevant products, biomaterials-based companies are generating roughly $99 \%$ of total sales, followed by cells and biomaterials $(1 \%)$ and stem cells $(<1 \%)$. Figure 3 shows statistics based on the three product types for companies in all four stages (preclinical, clinical, commercial, service). Although there are more stem cell-based companies (22) than biomaterials or cells and biomaterials (Fig. 3B), biomaterialsbased companies dominate the field in number of people employed (136,221) (Fig. 3C).

R\&D investment was highlighted in Figure 3A because it represents growth and expansion for the company. While biomaterials-based companies have the greatest total operating expenses, stem cell-based companies led in R\&D spending ( $\$ 6.2$ billion). Biomaterials-based companies had a large amount of R\&D spending as well ( $\$ 4.7$ billion), but R\&D spending only accounted for a much smaller proportion of their operating costs compared to stem cell companies. Cell and biomaterials-based companies had the smallest amount of spending dedicated to R\&D ( $\$ 100$ million). 


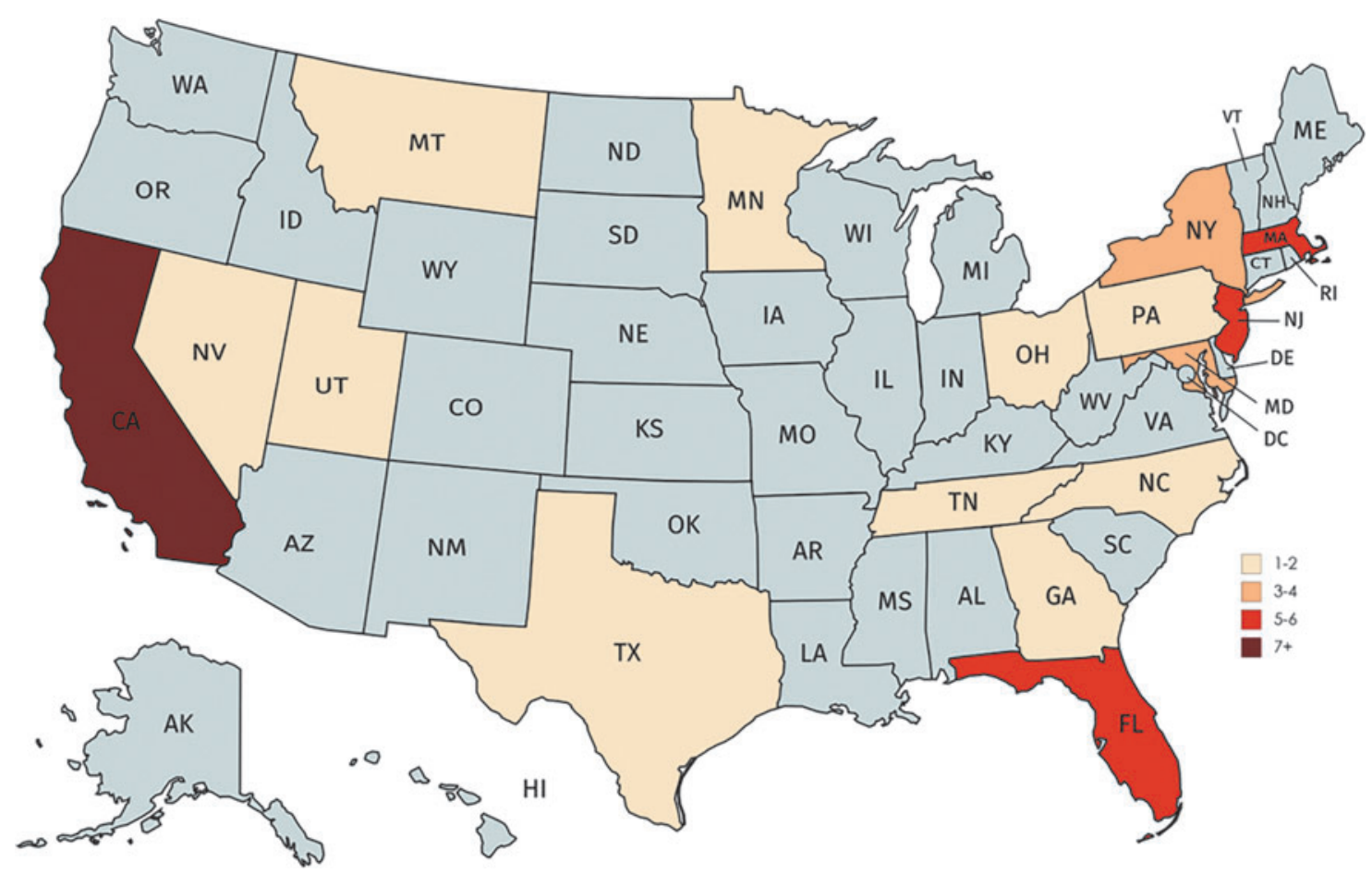

FIG. 1. Distribution of tissue engineering companies in the United States. Companies were plotted on a map of the U.S. based on the location of their principal executive office (created through mapchart.net(C).

In addition to product type, companies were also sorted based on their current development stage-commercial, clinical, preclinical, and service. Five companies were identified as service companies. They all provided stem cell services, such as cord banking. Together, the service companies spent $\$ 8.3$ billion in operating costs and made $\$ 16$ billion in sales in the 2017 fiscal year. Celgene contributed to over $80 \%$ of these financial statistics.

Highest operating costs (Fig. 4) were procured from companies in the commercial phase. Biomaterials-based companies account for the greatest portion of operating expenses, partially because there are more biomaterialsbased companies selling products than cells and biomaterials and stem cell companies combined. Stem cell-based companies make up the majority of the spending for both the clinical trials and preclinical development stages (Fig. 4).

There were 66 interventional clinical trials started or ongoing in the United States between June 2011 and March 2018 (Supplementary Table S2), which is around $0.21 \%$ of total interventional studies that were either completed or ongoing during the same period in the United States.
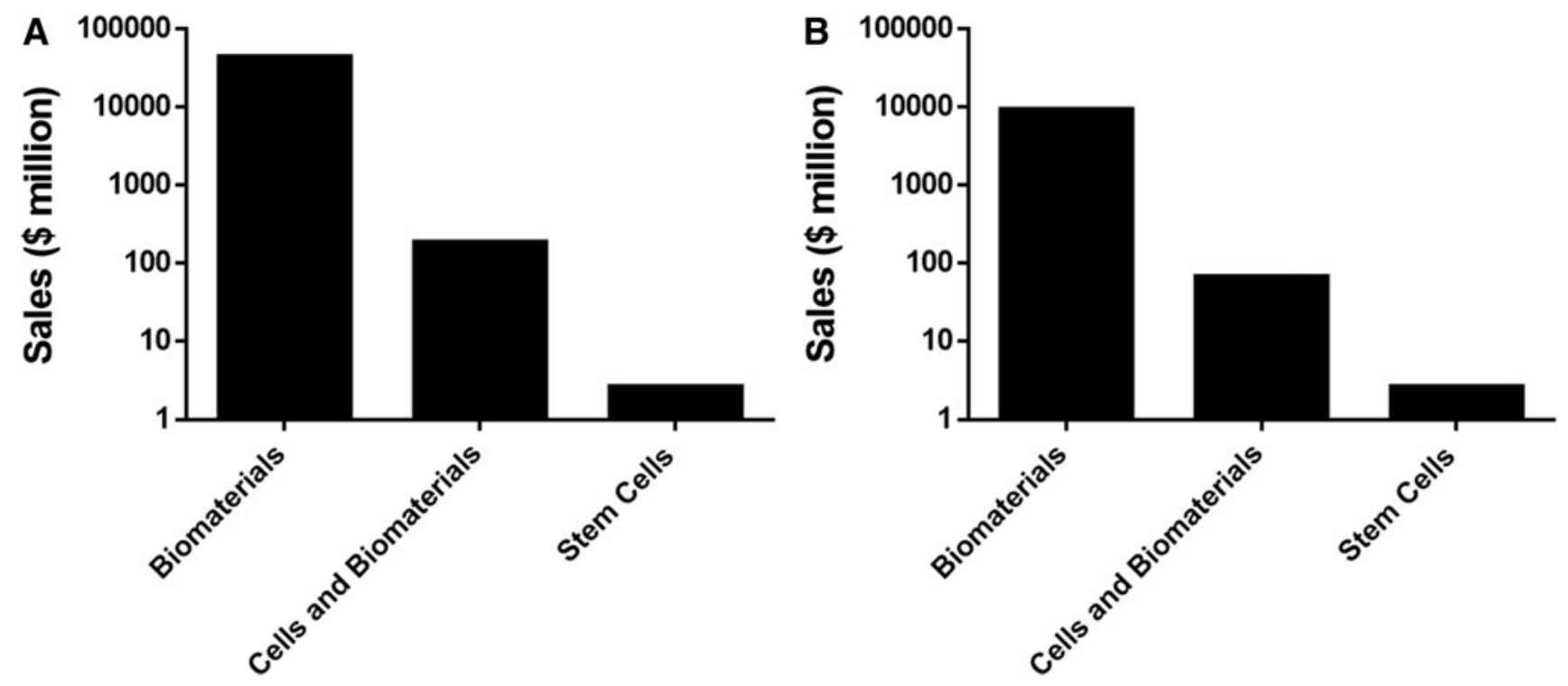

FIG. 2. Total sales by product type. Total sales from tissue engineering companies (A) and sales of tissue engineering products within tissue engineering companies (B) were sorted by product type. 

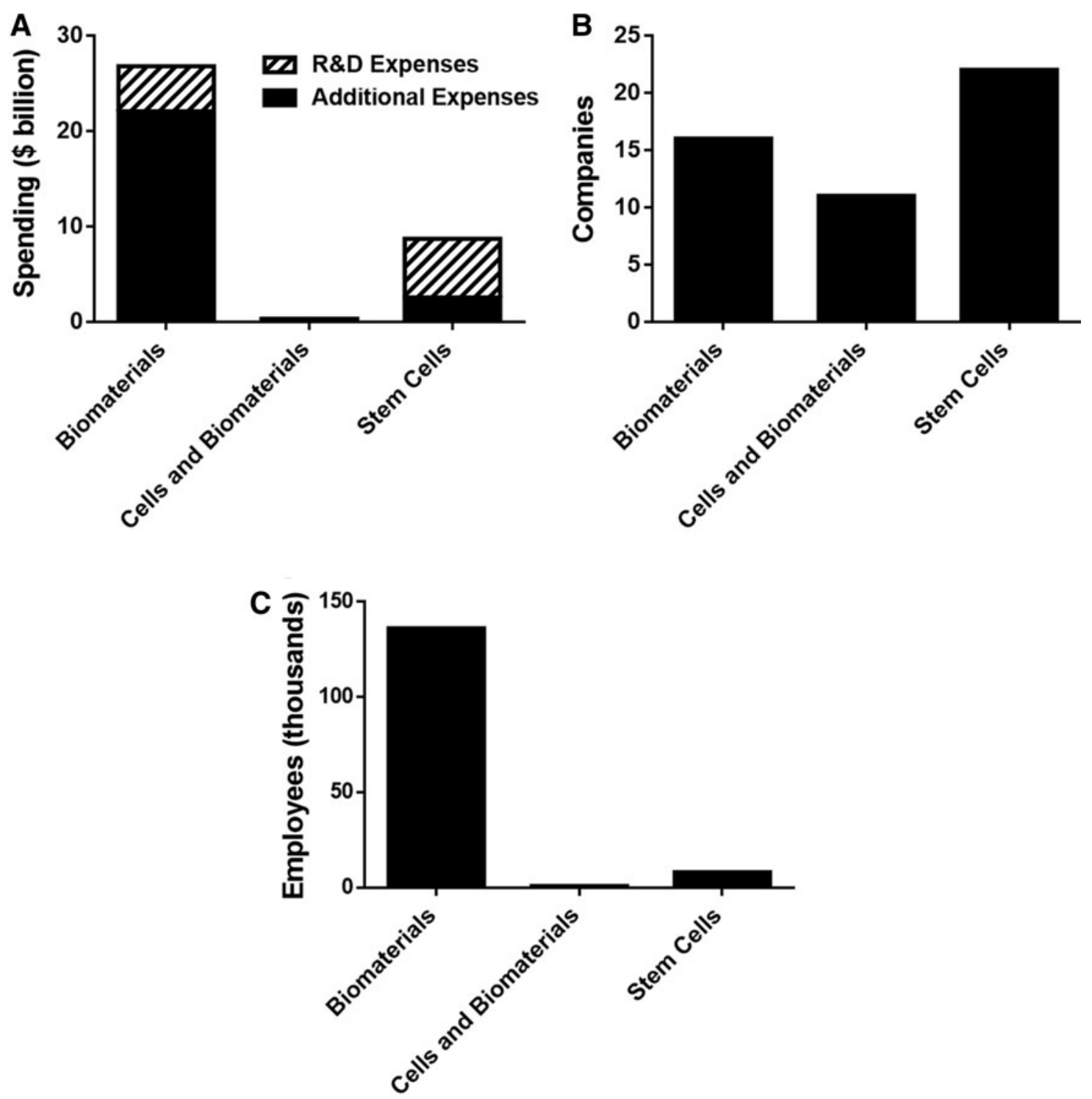

FIG. 3. Breakdown of tissue engineering company information. Operating expenses (A) were reported for companies by product type. The number of companies $(\mathbf{B})$ and the number of employees $(\mathbf{C})$ within each product category were also reported. R\&D, research and development.

As shown in Figure 5, clinical trials in the biomaterials category (39) comprised more than half of the total tissue engineering-related clinical trials, followed by cells and biomaterials (15) and stem cells (12) (Fig. 5C). There were 27 studies in the early stages of clinical trial (phase 1/2) and 11 in the late stage (phase $3 / 4$ ). There were 28 studies that did not have an FDA-designated phase; these studies included mostly efficacy tests for FDA-approved devices.

As expected, most of the clinical trials are being funded by the industry (51), followed by hospitals and academic/ research institutions (Fig. 5B). Out of 51 industry-funded clinical trials, $80 \%$ were being funded by public companies and the remaining $20 \%$ by private (data not shown).

\section{Discussion}

A number of reviews have been published since the first update on the TE industry was reported in $1995 .^{2,5-9}$ These have been very well-constructed reviews, but we found that the methods provided were not reproducible. Therefore, this review provides methods that are outlined in a way that can easily be reproduced and only included companies that have information publicly available. The drawback is that this review leaves limited room to make comparisons to the previously published reviews. In addition, only TE productspecific sales were identified and reported. All other financial information (Figs. 2-4) was reported for the total TE companies (Supplementary Table S1).

However, many trends hold true. In the latest review of the global TE marketplace, stem cell-based companies made up the majority of the spending in clinical and preclinical development stages, while biomaterials-based companies dominated the spending in commercial phase. ${ }^{2}$ As expected, the companies in the commercial stage of development had significantly higher operating costs than those at clinical or preclinical stages. ${ }^{2}$ The same trends hold true in the 

A
Commercial
B
Clinical

FIG. 4. Spending by development stage. Operating expenses were reported for companies by product type and development stage. The spending was categorized based on company product type within commercial (A), clinical (B), and preclinical (C) stages. The number of companies was also reported based on their development stage (D).
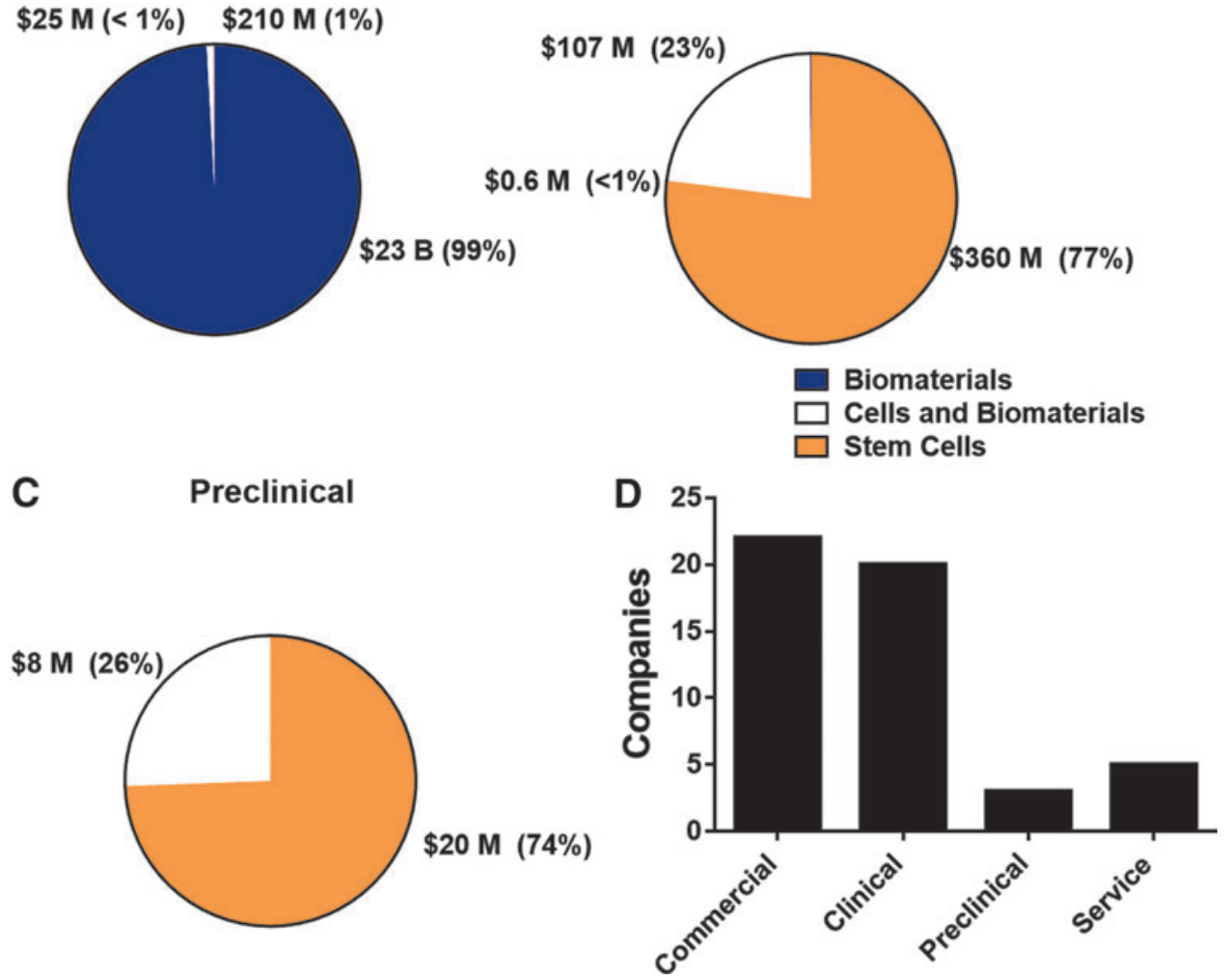

A Clinical Trial Phase

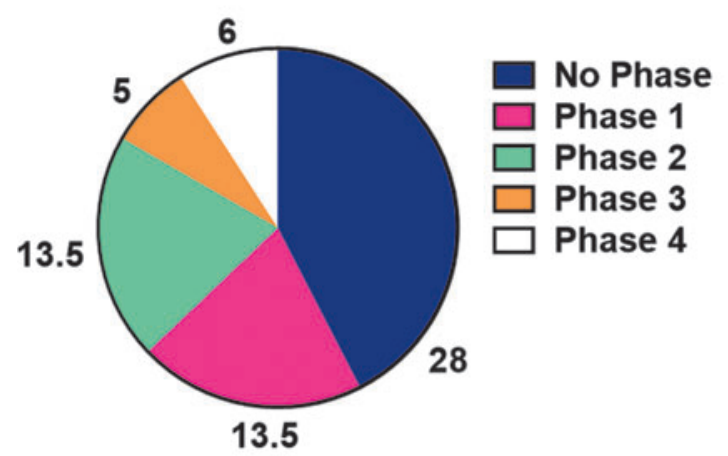

B Clinical Trial Sponsor

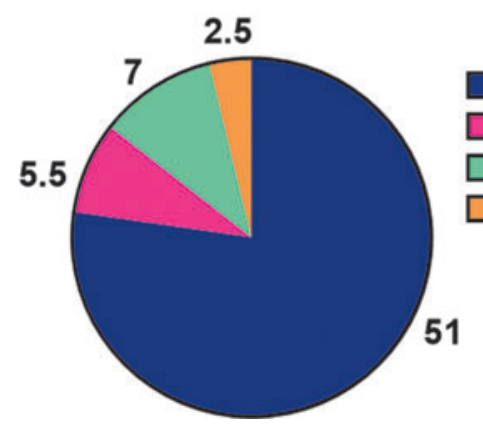

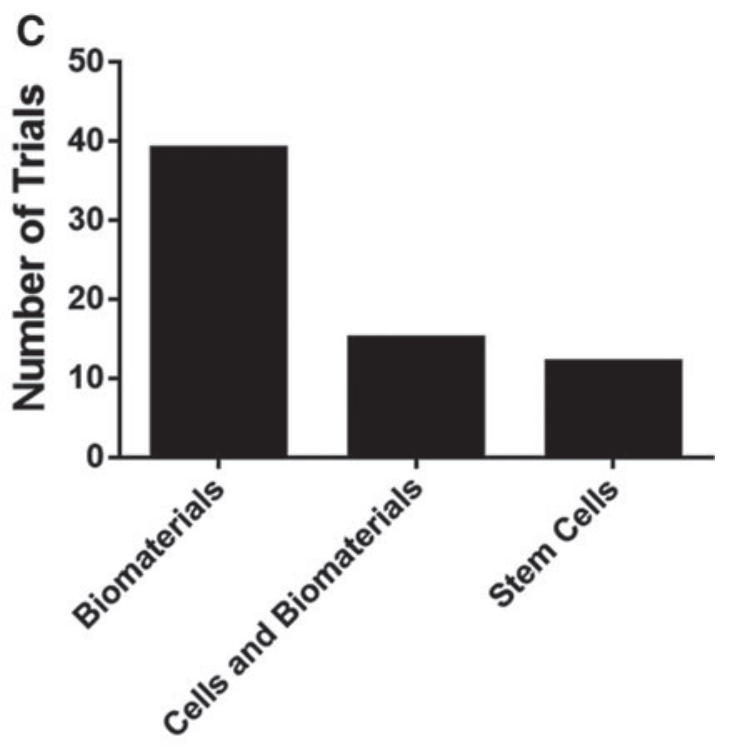

Industry

Academia/Research Institute

Hospital

Government

FIG. 5. Clinical trials. Information was gathered about clinical trials active between June 2011 and March 2018. The number of clinical trials in each clinical trial phase was reported (A). The sponsors of each clinical trial were reported (B). The clinical trials were organized into categories based on the therapeutic applications $(\mathbf{C})$. 
analysis of public companies within the United States from 2011 to 2018 presented in this review. The values cannot be compared between the previous review of global TE companies $^{2}$ and this review of public U.S.-based companies because of the differences in methods and scale. Conclusions can be drawn from this study that biomaterials-based companies are contributing to the bulk of the TE market in the United States, while the most R\&D spending among TE companies in the United States is going toward stem cell companies.

It is difficult to draw correlations between the industry and clinical trials data; most of the private companysponsored clinical trials are in the early stages, which we were unable to include in our financial analysis. Nevertheless, the number of clinical trials is a useful indicator of activity in the TE sector. When compared to overall number of clinical trials, TE is still considered to be a minor subset, with only $0.21 \%$ of total active clinical trials in the United States being categorized as TE, according to our criteria.

Within the field, more than half of the total TE-related clinical trials (roughly 77\%) are being sponsored by the industry; a similar trend is observed regardless of the category $(79.5 \%, 60 \%$, and $87.5 \%$ for biomaterials, cells and biomaterials, and stem cells, respectively). This indicates that, regardless of the scale of the field, there is at least continuous interest from the industry to push TE products out into the market.

External factors such as changes in FDA regulations and reimbursement or coding criteria can also affect product sales. Regenerative medicine products such as Dermagraft and Apligraf were severely impacted by the new compensation guideline proposed by Centers for Medicare and Medicaid Services (CMS). Under this new guideline, TE products are placed in the same therapeutic category as simpler and cheaper products, resulting in a much lower reimbursement percentage for using advanced TE products such as those listed above. ${ }^{10}$ This decision discouraged hospitals from using more expensive, technologically advanced products, as doing so would result in financial loss.

It is important to note that the number of active clinical trials during a given period of time is not an accurate indicator of successful future product development. We hope that comparing the results of the current status with that of a similar survey in future publications will provide better insight into (1) how many products are being pushed to enter the market, and (2) the revenue generated from products that receive FDA clearance. In addition, external factors such as changes in FDA regulations or CMS guidelines will influence the fate of TE products and will be closely correlated with how the field matures over time.

\section{Conclusions}

The TE industry has made immense progress over the past two decades, and it continues to show a strong footprint in the therapeutics market, with 49 public companies operating in the United States alone. Continuous efforts to acquire FDA clearance for TE products are underway, with 66 clinical trials ongoing or completed within the last 7 years. Future growth of the field will depend not only on the scientific innovations within the field but also on external circumstances such as FDA regulations and reimbursement guidelines by the federal government.

\section{Acknowledgments}

We acknowledge support in the field of tissue engineering by the National Institutes of Health (P41 EB023833 and R01 AR068073). MMS also acknowledges the National Science Foundation Graduate Research Fellowship Program and the Ford Foundation Predoctoral Fellowship Program.

\section{Disclosure Statement}

No competing financial interests exist.

\section{References}

1. Langer, R., and Vacanti, J.P. Tissue engineering. Science 260, 920, 1993.

2. Jaklenec, A., Stamp, A., Deweerd, E., Sherwin, A., and Langer, R. Progress in the tissue engineering and stem cell industry "are we there yet?" Tissue Eng B Rev 18, 155, 2012.

3. Mason, C., and Manzotti, E. Regenerative medicine cell therapies: numbers of units manufactured and patients treated between 1988 and 2010. Regen Med 5, 307, 2010.

4. Mason, C., Brindley, D.A., Culme-Seymour, E.J., and Davie, N.L. Cell therapy industry: billion dollar global business with unlimited potential. Regen Med 6, 265, 2011.

5. Lysaght, M.J. Product development in tissue engineering. Tissue Eng 1, 221, 1995.

6. Lysaght, M.J., Nguy, N.A.P., and Sullivan, K. An economic survey of the emerging tissue engineering industry. Tissue Eng 4, 231, 1998.

7. Lysaght, M.J., and Reyes, J. The growth of tissue engineering. Tissue Eng 7, 485, 2001.

8. Lysaght, M.J., and Hazlehurst, A.L. Tissue engineering: the end of the beginning. Tissue Eng 10, 309, 2004.

9. Lysaght, M.J., Jaklenec, A., and Deweerd, E. Great expectations: private sector activity in tissue engineering, regenerative medicine, and stem cell therapeutics. Tissue Eng A 14, 305, 2008.

10. Dodson, B.P., and Levine, A.D. Challenges in the translation and commercialization of cell therapies. BMC Biotechnol 15, 70, 2015.

Address correspondence to:

Antonios G. Mikos, PhD

Department of Bioengineering

Rice University

PO Box 1892

Houston, TX 77005

E-mail: mikos@ rice.edu

Received: May 21, 2018

Accepted: July 13, 2018

Online Publication Date: August 30, 2018 
Appendix Table A1. List of Public Companies in Tissue Engineering and Regenerative Medicine Sector as of March 2018

\begin{tabular}{|c|c|c|c|c|}
\hline Company name & Location & Sector & Stage & Website \\
\hline Acer Therapeutics & Newton, MA & Stem cells & Clinical trials & www.acertx.com \\
\hline Allergan & Madison, NJ & Biomaterials & Commercial & www.allergan.com \\
\hline Alliqua Biomedical & Yardley, PA & Biomaterials & Commercial & www.alliqua.com \\
\hline American CryoStem & Red Bank, NJ & Stem cells & Service & www.americancryostem.com \\
\hline Anika Therapeutics & Bedford, MA & Biomaterials & Commercial & www.anikatherapeutics.com \\
\hline Asterias Biotherapeutics & Fremont, CA & Stem cells & Clinical trials & www.asteriasbiotherapeutics.com \\
\hline Athersys & Cleveland, $\mathrm{OH}$ & Stem cells & Clinical trials & www.athersys.com \\
\hline Avita Medical & Valencia, CA & Cells and biomaterials & Commercial & www.avitamedical.com/us \\
\hline Axogen & Alachua, FL & Biomaterials & Commercial & ir.axogeninc.com \\
\hline Biocardia Lifesciences & San Carlos, CA & Cells and biomaterials & Commercial & www.biocardia.com \\
\hline Biorestorative Therapies & Melville, NY & Cells and biomaterials & Preclinical & www.biorestorative.com \\
\hline BioTime & Alameda, CA & Stem cells & Clinical trials & www.biotimeinc.com \\
\hline $\begin{array}{l}\text { BrainStorm Cell } \\
\text { Therapeutics }\end{array}$ & New York, NY & Stem cells & Clinical trials & www.brainstorm-cell.com \\
\hline Caladrius Biosciences & Basking Ridge, NJ & Stem cells & Clinical trials & www.caladrius.com \\
\hline Capricor & Beverly Hills, CA & Cells and biomaterials & Clinical trials & www.capricor.com \\
\hline Celgene & Summit, NJ & Stem cells & Service & www.celgene.com \\
\hline Celyad & New York, NY & Stem cells & Clinical trials & www.celyad.com \\
\hline Cesca Therapeutics & Rancho Cardova, CA & Stem cells & Service & www.cescatherapeutics.com \\
\hline Cord Blood America & Las Vegas, NV & Stem cells & Service & www.cordblood-america.com \\
\hline CryoCell & Oldsmar, FL & Stem cells & Service & www.cryo-cell.com \\
\hline Cryolife & Atlanta, GA & Biomaterials & Commercial & www.cryolife.com \\
\hline Cytori Therapeutics & San Diego, CA & Stem cells & Commercial & www.cytoritx.com \\
\hline Exactech & Gainesville, FL & Biomaterials & Commercial & www.exac.com \\
\hline Fate Therapeutics & San Diego, CA & Stem cells & Clinical trials & www.fatetherapeutics.com \\
\hline Geron & Menlo Park, CA & Stem cells & Clinical trials & www.geron.com \\
\hline Histogenics & Waltham, MA & Cells and biomaterials & Clinical trials & www.histogenics.com \\
\hline Integra LifeSciences & Plainsboro, NJ & Biomaterials & Commercial & occ.integralife.com \\
\hline $\begin{array}{l}\text { International Stem Cell } \\
\text { Corporation }\end{array}$ & Carlsbad, CA & Stem Cells & Clinical trials & www.internationalstemcell.com \\
\hline InVivo Therapeutics & Cambridge, MA & Stem cells & Preclinical & www.invivotherapeutics.com \\
\hline Medtronic & Minneapolis, MN & Biomaterials & Commercial & www.medtronic.com \\
\hline MiMedx Group & Marietta, GA & Biomaterials & Commercial & www.mimedx.com \\
\hline Neuralstem & Rockville, MD & Stem cells & Clinical trials & www.neuralstem.com \\
\hline Nuo Therapeutics & Gaithersburg, MD & Cells and biomaterials & Commercial & www.nuot.com \\
\hline Organovo & San Diego, CA & Cells and biomaterials & Commercial & www.organovo.com \\
\hline Osiris & Baltimore, MD & Cells and biomaterials & Commercial & www.osiris.com \\
\hline Q Therapeutics & Salt Lake City, UT & Stem Cells & Preclinical & www.qthera.com \\
\hline Regenicin & Little Falls, NJ & Cells and biomaterials & Clinical trials & www.regenicin.com \\
\hline RTI Surgical & Gainesville, FL & Biomaterials & Commercial & www.rtix.com/en_us \\
\hline SanBio & Mountain View, CA & Stem cells & Clinical trials & www.san-bio.com \\
\hline SeaSpine & Carlsbad, CA & Biomaterials & Commercial & www.seaspine.com \\
\hline Smith \& Nephew & Fort Worth, TX & Biomaterials & Commercial & www.smith-nephew.com \\
\hline $\begin{array}{l}\text { Taxus Cardium } \\
\text { Pharmaceuticals }\end{array}$ & San Diego, CA & Biomaterials & Clinical trials & www.cardiumthx.com \\
\hline Tissue Regenix & San Antonio, TX & Biomaterials & Commercial & www.tissueregenixus.com \\
\hline U.S. Stem Cells & Sunrise, FL & Stem cells & Clinical trials & www.us-stemcell.com \\
\hline Vericel & Cambridge, MA & Cells and biomaterials & Commercial & www.vcel.com \\
\hline VistaGen Therapeutics & Durham, NC & Stem cells & Clinical trials & www.vistagen.com \\
\hline Vital Therapies & San Diego, CA & Cells and biomaterials & Clinical trials & www.vitaltherapies.com \\
\hline Wright Medical Group & Memphis, TN & Biomaterials & Commercial & www.wright.com \\
\hline Xtant Medical & Belgrade, MT & Biomaterials & Commercial & www.xtantmedical.com \\
\hline
\end{tabular}

